\title{
THE ACADEMIC EXPERIENCES OF GRADE 12 TOP ACHIEVERS \\ IN MAINTAINING EXCELLENCE IN FIRST-YEAR UNIVERSITY \\ PROGRAMMES
}

\author{
T. P. Mahlangu* \\ e-mail: thoko.dima@vodamail.co.za
}

\author{
W. J. Fraser* \\ e-mail: William.fraser@up.ac.za
}

*Department of Science, Mathematics and Technology Education

University of Pretoria

Pretoria, South Africa

\section{ABSTRACT}

This article reports on a study focusing on the academic experiences of top achievers in maintaining excellence in first-year university programmes. The study investigated in particular the academic experiences of Grade 12 top achievers from Mpumalanga, South Africa, at various universities. A mixed methods approach was used to collect data, making use of a convenience sample of $(n=14)$. Data was generated using a closed-ended questionnaire, students' academic records and standardised individual interviews conducted with eleven students. The results indicate that academic excellence in the first year is influenced by self-discipline, self-motivation, interest in the course, self-confidence, academic preparedness, effort and the belief students have about themselves. The investigation revealed that, generally, top achievers' academic performance in the first year denoted what Viljoen and Deacon $(2013,242)$ term 'academic fit'. The findings of the study emphasise the significant influence of positive 'compelling forces' at universities that assist first-year students in adapting to the university environment.

Keywords: academic performance, top achievers, experiences, perceptions, first-year university, attribution theory, support structures, academic experiences

\section{INTRODUCTION}

Studies conducted in different parts of the world and in South Africa on the transition experiences of students entering tertiary education for the first time reveal that students encounter challenges that often lead to them quitting their studies. These challenges range from loneliness or homesickness to a lack of funds to sustain their stay at college or university (Modipane 2011, 1593). Therefore, this study investigated the way first-year university students used the available programmes and services that were meant to assist and develop them to cope 
with the academic demands of university.

Miller, Bradbury and Lemmon $(2000,166)$ argue in this regard that part of the current attempt to transform higher education is to ensure that students from diverse contexts in terms of educational, linguistic and cultural backgrounds can be accommodated within a common system. It is therefore not surprising to note that some researchers such as Du Rand and Viljoen (2000, 12) have also realised that students studying in South African higher education institutions (HEIs) are vulnerable to changing 'epistemic contexts and postures'. In their study on students' experiences of challenges and threats, Van Heerden, Myburgh and Poggenpoel $(2001,158)$ used the term 'epistemic posture', which relates to the manner in which people 'do knowing' and their presumptions concerning the 'epistemic meta-narrative'.

This study was further motivated by Ochse's (2003, 67-68) argument that our performance is determined by both our perceptions of our ability (whether accurate or inaccurate) and our expectancies, which influence our motivation and persistence. Interestingly, Ochse (2003) concludes by warning that students who are not successful may be crippling themselves by perceiving themselves as not having the potential or ability and not believing they will succeed.

\section{LITERATURE REVIEW}

The literature review explores various factors that determine academic performance in the first year of university study. Peterson, Rubie-Davies, Elley-Brown, Widdowson, Dixon and Irving $(2011,2)$ reveal in this regard that a number of studies have looked at factors that influence or predict student success (e.g. teacher-student relationships, ability, effort, self-regulated learning, parental involvement) but there is a dearth of literature on the value students place on these influences. Hence, Peterson et al. $(2011,2)$ point out that there is little doubt that students who do take responsibility for their learning (i.e. success or failure) perform better. The interviews that were conducted (in this study) afforded the students an opportunity to cite the factors that contributed to their academic performance in their first year at university, irrespective of the programmes they were enrolled in.

Scott $(2009,19)$ makes the important point that the first year of higher education is an educational stage that has a powerful influence on future success for both the individual student and the sector as a whole. According to this author (Scott 2009, 19), first-year experiences in terms of cognitive, personal and social development largely determine students' first-year performance, which is a key foundation for advanced study (including postgraduate study) and which is vital to intellectual development in all spheres, including the future staffing of the 
university. However, Muller, Swanepoel and De Beer $(2010,64)$ are of the opinion that no single intervention or attribute influences an outcome (such as performance) in isolation and that outcomes are usually influenced by a combination of interacting forces.

This research was initiated in order to identify the critical factors that potentially determine students' academic achievement in HEIs. This initiative could play a significant role in assisting tertiary institutions to develop academic programmes and provide services that cater directly for the needs of their students. Hence, Affendey, Paris, Mustapha, Nasir Sulaiman and Muda $(2010,836)$ state that in order to help improve intervention strategies and support services for students who perform poorly in their studies and to implement such strategies and services as early as possible in the students' academic career, the attributes that contribute most significantly to students' academic performance should be identified. This argument is well phrased by Bitzer and Troskie-De Bruin (2004, 119), who maintain that knowledge about the various kinds of experiences students are exposed to, and the benefit (or lack thereof) derived from them while they or students participate in higher education, is important if any useful inferences are to be made.

\section{THEORETICAL FRAMEWORK}

To generate discussion, facilitate understanding and make meaning of the study, Weiner's (1985) attribution theory was used. Attribution theory is also known as explanation theory, as it actually refers to what we attribute our success and failure to. In defining attributions, Nokelainen, Tirri and Valimaki $(2007,66)$ quote Heider (1958), who was the first to refer to the different reasons that people give for particular results, such as success or failure in a task, as 'attributions'. Furthermore, Schunk and Meece (2008) simplify this by explaining that attribution or causal explanation is what a person believes is the cause of an outcome, even though it may not be the real cause.

Weiner's (1985) theory postulates that the perceived causes of success and failure share three common properties, namely, locus, stability and controllability, with intentionality and globality as other possible causal structures. In line with the study conducted by Polaki and Nenty (2001), Vallerand and Richer $(1988,704)$ mention that, Weiner suggests that causal attributions can be categorised according to a $2 \times 2 \times 2$ (internal/external locus of causality $\mathrm{x}$ stability/instability x controllability/uncontrollability) orthogonal taxonomy. One example of such causal attribution relates to task difficulty, which can be seen as being external, stable and uncontrollable, while the effort involved may be seen as being internal, unstable and controllable (Weiner 1985, 551). 
First-year university top achievers (students) might attribute their academic success in first year to different individual backgrounds and university experiences. However, these do not exclude their experiences in the university environment, including such factors as being away from home, their university accommodation, choosing when to attend classes and to write and submit assignments, and social engagements.

Interestingly, Tomai and Forbus $(2008,1)$ allude to another aspect that contributed positively to this study; that is, that the aim of attribution theory, as developed by Heider (1958), is to investigate the circumstances that will lead a perceiver, through an attribution process, to ascribe some behaviour, event or outcome to an internal disposition of the person involved as opposed to an environmental condition.

\section{RESEARCH DESIGN AND METHODOLOGY}

In this study, I worked from a pragmatic research paradigm in terms of which individuals who subscribe to it focus on the outcomes of the research, the actions, the situations and the consequences of inquiry, rather than antecedent conditions (see Creswell 2007, 22). Johnson and Christensen $(2012,32)$ posit in this regard that pragmatism is a philosophical position where what works is what is important or 'valid'. Moreover, pragmatism is generally considered to be a way of dealing with issues or problems in a more practical way instead of strictly following a set of ideas. According to Ivankova, Creswell and Plano Clark (2011, 265), pragmatists believe that the truth is 'what works' best for understanding a particular research problem. This means that pragmatism is not committed to any one system of philosophy and reality.

The study was conducted by means of a mixed methods design. The aim of the research was to gather information concerning the academic experiences of matric top achievers in their first-year university programmes. I chose a mixed methods research design for this study because it suited the objectives and provided answers to the research questions in a single study. One fundamental principle of mixed methods research that influenced my choice is that it combines methods in a way that achieves complementary strengths and non-overlapping weaknesses (Punch 2009, 290; Johnson and Christensen 2012, 51).

This article reports on a study that employed an explanatory, sequential mixed methods design. This design was applied because, as Creswell and Plano-Clark $(2011,185)$ emphasise, the intention was to use qualitative data to provide more detail about the quantitative results, and the individuals best suited to do this are the ones who contributed to the quantitative data set. 


\section{Research procedures}

Permission to conduct research on the matric top achievers was sought from the Mpumalanga Department of Education. Thereafter, matric top achievers for the years 2011 and 2012 were traced, contacted and informed about the project and were subsequently asked whether they would participate in the study. Those top achievers who were willing to take part in the study were requested to sign a consent form prior to participation. The selection of these first- and second-year university students was purposeful because I needed information particularly on the academic experiences of matric top achievers in their first year at university.

During the study, data was collected from 14 matric top achievers (students) who were in either their first or their second year at university. A closed-ended questionnaire with a few open-ended items was employed. A four-point Likert-type scale was used on which participants were required to indicate their perceptions, ranging from totally disagree (1) to totally agree (4). The students were later invited to participate in a qualitative study (i.e. interviews) as a follow up to the data provided in the questionnaires. Eleven of the fourteen students subsequently participated in standardised once-off open-ended interviews which were conducted individually. My use of a standardised, open-ended interview was supported by its formal and manageable nature. The interview questions differed from those in the questionnaire although they were based on the data obtained from the questionnaire. The data collection process also included document analysis, as the sampled students' matric results and first-year university academic results were analysed to supplement the qualitative data.

\section{DATA ANALYSIS}

Since the study was by nature a sequential design, I first analysed the quantitative data collected, subsequently allowing it to inform the qualitative second phase of the study. Accordingly, the quantitative data obtained from the questionnaire was transformed into descriptive statistics, including the tallying of frequencies, and used for data analysis. I described the data value of variables by constructing a frequency distribution. The data collected from the interviews was transcribed and then coded, classified and categorised logically. The qualitative results were presented in the form of themes and subthemes which were supported by quotations.

\section{DISCUSSION OF THE RESULTS}

The study is located within the higher education field, which placed the research at the centre of first-year students' transition into university and students' academic success. I drew on a 
publication by Pascarella and Terenzini (2005), who worked on the effects of college on students. In their study, Pascarella and Terenzini $(2005,635)$ argue that much of the research on college impacts concentrates on changes between the first and second years or between enrolment and graduation.

Interestingly, Ngidi (2007) has rightly argued that the long-term goal to increase participation rates in higher education in South Africa in the face of low graduation rates, highlights the need for universities to take a fresh look at all the factors that determine whether or not students are successful. Therefore, it is against this background that there are suggestions that although there is a need to have appropriate entry requirements for higher education, there is also a need to pay more careful attention to other pre-enrolment factors such as cognitive ability and personality traits, as well as post-enrolment factors that influence students' academic success (Ngidi 2007, 718).

\section{Self-actualisation performance}

Generally, the findings of this study reveal that participants attributed their performance or behaviour in first-year university either to forces within themselves or partially to forces external to them. This is reinforced by Heider (1958, in Petri and Govern 2004, 318), who points out that, logically, one could attribute behaviour either to forces within the individual (dispositions) or to forces external to the individual (situational factors). For example, dispositions include factors such as needs, wishes, emotions, abilities, intentions and one's willingness to work. The findings of this study also revealed that participants attributed their academic experiences or performance to both dispositional (internal) attribution and situational (external) attribution.

From the data obtained in this study, the following aspects were listed as the most important regarding maintaining academic excellence in the first year: self-discipline, selfmotivation, interest in the course, self-confidence, academic preparedness, effort, and the beliefs students had about themselves. These findings are in line with those of previous studies conducted, which reported that students viewed self-motivation and self-discipline to be of importance as factors contributing to success (Fraser and Killen 2005, 36). All these aspects confirm Tinto’s (1975) intellectual development ideology. According to Tinto (1975, 104), intellectual development represents an integral part of the person's personal and academic development, which can be viewed as a more intrinsic form of reward. Advancing this statement, Tinto $(1975,105)$ further elaborates that intellectual development has also been found to be related to persistence in college, as it is an integral part of the person's personality 
development and is a reflection of their intellectual integration into the academic system of the college.

\section{Individual characteristics and academic achievement}

The most prominent finding regarding individual characteristics (dispositional factors) that were cited as having contributed to students' performance and persistence in first-year university studies is self-motivation and interest in the course. More pertinent to the theoretical model used here is the direct relationship found by several studies between self-motivation and persistence in higher education, leading to academic success (Deci and Ryan 2002; Killen, Marais and Loedolff 2003; Fraser and Killen 2005; Sikhwari 2007; Schreiner and Hulme 2009). The findings thus confirm Tinto’s $(1975,102)$ position that discussions of motivation suggest that if an individual identifies him or herself as a future college graduate, they will in fact be more motivated to complete the college degree programme.

One can undoubtedly say that motivation on the part of students does influence goal commitment. Hence, Tinto $(1975,102)$ reported that, as suggested by a number of researchers, once the individual's ability is taken into account, it is their commitment to the goal of college completion that is most influential in determining college persistence. It would therefore seem logical that given the importance of motivation in students' academic success, such attributions should also be prioritised by HEIs in their programmes for first-year students. Indeed, according to findings of this study, motivation was found to be one of the most common attributes cited by students for their success and is evident in the academic achievement of participants in their first year at university. This confirms Zulu's $(2008,33)$ finding that motivation has been cited in many studies as a potential factor in students' academic success.

Nevertheless, the findings of this study also revealed that the first-year students encountered serious challenges at university. The most common challenges raised by participants were related to the heavy academic workload, adaptation and the unstructured curricula. It is important to note that these findings reaffirm those of Bitzer and Troskie-De Bruin (2004), who found that students' perceptions of the workload determine the level of their effort. This finding confirms what Pascarella and Terenzini’s (2005, 61) study revealed that, for students, the transition to college provides a form of culture shock requiring significant social and psychological relearning in the face of encounters with new ideas, new teachers and friends with different values and beliefs; new freedoms and opportunities; and new academic, personal and social demands. This finding is well phrased by Feldman and Newcomb (1969), in Pascarella and Terenzini (2005, 61), who characterised the freshman year as a combination 
of desocialisation pressures to unlearn certain attitudes, values, beliefs and behaviours. Students also have to learn new attitudes, values and beliefs and participate in a new culture and social order (i.e. socialisation pressures).

\section{Adjustment and adaptation to university challenges}

Two important elements of adjustment or adaptation were identified by the findings of this study. Firstly, that adjustment to university is a crucial determinant of academic performance. Secondly, a key trend that was noted (based on students' academic records) was that top achievers' academic performance improved in the second term or semester after they had adapted effectively (document analysis). This finding confirms one of the arguments of Morosanu, Handley and O’Donovan (2010) that coping at university ultimately depends, despite all efforts on the part of staff, on students' own initiatives to seek or use support from the pool of available choices.

Adaptation in particular was repeatedly mentioned by participants as the major challenge they encountered in their first year of study, which suggests that it is imperative for students to adapt and integrate appropriately into the university or institution. In addition, the findings reveal that in terms of academic success, it is important for students to integrate positively into the university (institution). Accordingly, Pascarella and Terenzini $(2005,54)$ define integration as the extent to which the individual shares the normative attitudes and values of peers and faculty in the institution and abides by the formal and informal structural requirements for membership in that community or in subgroups of it.

Adaptation as a variable is located within the individual's disposition (internal force). In other words, the individual's attitudes to or perceptions of the university environment determine whether or not the student will adapt positively. However, the very same environment might also dictate to an individual such that it becomes difficult if not impossible for them to adapt easily to the university environment. This finding is in accord with Tinto's $(1975,111)$ argument that:

It is the characteristics of the institution, its resources, facilities, structural arrangements and composition of its members that place limits upon the development and integration of individuals within the institution and that lead to the development of academic and social climates or 'presses' with which the individual must come to grips.

Based on the discussion above, my position is that both heavy academic workloads and unstructured curricula as challenges might be linked to the problem of adaptation or adjustment experienced by first-year students at the universities. Following the findings of this study, my 
argument is confirmed by Zulu (2008, 30-31) who argues that during the first year the nature of academic and social adjustment experienced by a student can determine whether he or she persists or drops out of university.

Suffice it to say that the findings of this study replicate those of Bitzer and Troskie-De Bruin (2004), who argue that workload is one of the factors that influence the academic adaptation process during the first year in higher education. Consequently, these authors (Bitzer and Troskie-De Bruin 2004, 124) warn that the danger with the increase in time necessary to cope with the workload at university is that students will not be able to adapt effectively, either because they do not perceive the demands of the task correctly or because they do not know how to manage their time effectively.

Zulu (2008, 31) further suggests that it is crucial for any institution to focus attention on providing the kinds of academic experiences that would ensure that first-year students succeed and persist in their academic careers. Theoretically, care should be taken that external factors (i.e. the university environment and experiences) do not have a negative impact on the students' adaptation and integration into the university because that would then determine students' commitment to the university and their individual goal of succeeding academically.

In their argument, Pascarella and Terenzini $(2005,54)$ warn that negative interactions and experiences tend to impede integration and distance the individual from the academic and social communities of the institution, thereby reducing commitment to both goals and institution and promoting the individual's ultimate withdrawal. Similarly, Bitzer and Troskie-De Bruin (2004, 121) warn that negative or malintegrative experiences serve to weaken student intentions and commitment, especially commitment to the institution, and thereby enhance the likelihood of them leaving. On that note, Pascarella and Terenzini $(2005,54)$ also reported that as integration increases, it strengthens students' commitment to both their personal goals and to the institution through which these goals may be achieved.

Despite the challenges encountered by participants in adjusting to university life, the findings of this study revealed that participants were nevertheless able to adapt to university, irrespective of the negative factors that hinder integration, adaptation and living up to the demands of the university environment. In their study on retention and predicting first-year success, Lourens and Smit $(2003,169)$ point out that commonality between integration and satisfaction is crucial to academic performance and persistence, and that student satisfaction is closely related to student retention and is key to academic withdrawal. According to these researchers, this means that students' satisfaction with all aspects of the university is significantly related to their perceptions of things and even the outcome (i.e. their behaviour). 
As a result, the quality of student experience within the university in both academic and social systems is very important in determining academic performance and success. Consequently, Holmberg (2001, in Fraser and Killen 2005, 37) suggests that students who feel a strong personal connection with their learning institution are likely to be more motivated and to study more effectively.

\section{The role of the school to future performances}

The findings of the current study further confirm the importance of students' previous academic performance and high school experiences. This is also highlighted by Killen, Marais and Loedolff $(2003,156)$, who state that the tendency of students to approach university study in a particular way may be attributed to their past educational experiences. Accordingly, Petri and Govern $(2004,324)$ maintain that Weiner's approach assumes that the inferences we make about our abilities result primarily from earlier experiences. In addition, past successes will lead us to conclude that we have certain abilities in certain areas while past failures will reduce our belief in those abilities. In this case, by virtue of their being top achievers in matric, the participants in this study seemed to have attributed most of their achievement to their own ability and the effort they put into tasks. This is in line with Bitzer and Troskie-De Bruin (2004, 123), who in their discussion on academic factors maintained that insufficient effort is often a reason for failure. Furthermore, these authors (Bitzer and Troskie-De Bruin 2004, 124) maintain that students' perception of an academic task, their perception of their own ability and their belief that they can succeed at a specific task determine the effort they will put into the task. In this regard, Weiner (1985) argues that we tend to perceive ourselves as having expended more effort when we are successful at a task.

Theoretically, the findings of this study also confirm the argument made by Pascarella and Terenzini (2005, 54), based on the work of Tinto (1975), that students enter a college or university with a variety of patterns of personal, family and academic characteristics and skills. These include initial dispositions and intentions with respect to college attendance and personal goals. According to Pascarella and Terenzini (2005, 54), these intentions and commitments are subsequently modified and reformulated on a continuing basis through a longitudinal series of interactions between the individual, the structures and members of both the academic and the social systems of the institution.

Generally, top achievers’ academic performance in the first year denotes what Viljoen and Deacon $(2013,242)$ term 'academic fit'. According to these authors (Viljoen and Deacon 2013, 242), academic fit is 'the matching of or compatibility between the student's personal 
characteristics and those of the course and institution'. This is not surprising because research on higher education has shown that good career choices are the best predictors of students' success.

\section{The individualisation of own performance}

At this point the findings also revealed that some of the participants did not consider groupwork to be important or of assistance in their studies. These findings contradict those of Bitzer and Troskie-De Bruin $(2004,123)$, who found that, in general, students were very confident of their ability to work together in a group. The participants of the current study believed that their own efforts and willingness to adapt to the academic expectations of the university were all they needed. This therefore means that by having an effective 'self-regulatory system', the participants were able to strike a balance in their activities within the university so as to satisfy the academic needs. This is important because whether internal or external, stable or unstable, controllable or uncontrollable, according to Weiner's model, the attributions accorded to a particular event determine its influence on subsequent academic outcomes, including expectations, affect, perceived control and behaviour (Fraser and Killen 2003, 260; Killen, Marais and Loedolff 2003, 156). Consequently, Killen, Marais and Loedolff $(2003,156)$ argue that from this point of view, students' perceived reasons for success or failure may have a stronger influence on their persistence or withdrawal than the actual reasons. As a result, I can proudly say that based on the findings, participants were doing well academically because they mainly attributed any unsatisfactory academic achievement on their part to personal, unstable and controllable causes such as lack of effort, laziness and lack of time management, which they could personally rectify and improve. Shermer (1997, in Petri and Govern 2004, 317) thus postulates that causal reasoning is evolutionarily adaptive; it helps us to understand and consequently control our environment. In addition to the position above, it is important to note that these attributions of human behaviour also stem from a need to control our environment.

Seemingly, the factors perceived by first-year students as contributing to their academic success suggest the importance of the informal education that takes place right before coming to university (at home). These findings are in accord with previous studies, hence Polaki and Nenty $(2001,50)$ advise that it is important that students are trained by parents early on in the acculturation process to make effort-related attributions for performance and to see their success as depending more on effort than on ability.

Regarding the issue of seeking support to maintain academic excellence, the results revealed that students can be loosely divided into two groups, namely, those who choose and 
are able to rely on themselves and those who normally resort to seeking help elsewhere. This finding confirms the statement noted in a study conducted by Morosanu, Handley and O’Donovan (2010) that while some students might choose to manage alone, others resort to supportive 'ties' in coping with their first-year problems. In this regard, Weiner $(1985,555)$ argues that perceived causality differs from one person to the next and within an individual on occasions.

According to the findings of this study, attributions for success are perceived as being more stable, controllable and internal than are attributions for under-achievement or failure conditions. Therefore, the results of this present study replicate the findings of Fraser and Killen (2003, 260) where senior students in particular attributed success to their own efforts and failure to their lecturers. Despite the fact that the findings revealed that students attributed their academic success mostly to factors within themselves, namely, dispositions or internal factors, the prevailing conditions conducive to learning and teaching at university, that is, situational factors, created what I call ‘compelling forces' for students to put in more effort and persist in their studies. This affirms Astin's (1993, in Bitzer and Troskie-De Bruin 2004, 120) finding that true educational excellence lies in an institution's ability to influence its students and staff favourably, to enhance their intellectual and scholarly development and to make a positive difference in their lives. This then means that the most 'excellent' institutions are those that have the greatest impact on and add the most value to students' knowledge, skills, attitudes and personal development.

This investigation practically revealed three important aspects which were highlighted by the findings:

1. The importance of pre-entry attributes (especially the internal factors that students have when entering university) as the strongest predictor of academic success.

2. The power to excel or succeed academically is located within an individual. Theoretically, this means that one's attempt to change achievement depends upon how much 'power' one has over an attribute.

3. Positive external (situational) factors in the university that students found at their disposal are of significance to students' persistence and academic success. Hence, adaptation is the key to integration into the university and academic success.

\section{CONCLUSION}

Unless students start to realise individually that the power to succeed academically lies within 
themselves, they will not improve or perform as expected at university, especially in the first year. Generally, attribution theory also implies that any attempt to change one's achievement depends upon how much 'power' one has over an attribute. In other words, if students do not have much power to change an attribute that promotes failure, hopes for improved performance in the future remain dim (Polaki and Nenty 2001, 48-49). Students' adjustment or adaptation to university is an important element to consider when providing support to improve student success or academic achievement.

It also needs to be explained that this study partially provided answers to the concern of Bitzer and Troskie-De Bruin (2004) that institutions consider a learner's academic performance within the top ten class positions at school as an additional possible indicator of academic success in the higher education environment. This is a factor that has not yet been tested empirically.

This study had the objective of ensuring effective mentoring and academic success for first year university students. This might require successful first-year university students to reflect on factors that might have positively contributed to their academic excellence or success in first year. This process would assist universities in the development of support programmes for first-year students and to improve student performance and retention.

Future research will attempt to explore the way students' experiences at university and their expectations of lecturers influence their academic performance or success.

\section{REFERENCES}

Affendey, L. S., I. H. M. Paris, N. Mustapha, M. Nasir Sulaiman and Z. Muda. 2010. Ranking of influencing factors in predicting students' academic performance. Information Technology Journal 9(4): 832-837.

Bitzer, E. and C. Troskie-De Bruin. 2004. The effect of factors related to prior schooling on student persistence in higher education. South African Journal of Education 24(2): 119-125.

Creswell, J. W. 2007. Qualitative inquiry and research design: Choosing among five approaches. 2nd edition. Thousand Oaks, London, New Delhi: Sage Publications.

Creswell, J. W. and V. L. Plano Clark. 2011. Designing and conducting mixed methods research. Los Angeles, London, New Delhi, Singapore, Washington DC: Sage Publications.

Deci, E. L. and R. M. Ryan. 2002. The paradox of achievement: The harder you push, the worse it gets. In Improving academic achievement: Impact of psychological factors on education, ed. J. Aronson, 61-87. San Diego, London: Academic Press.

Du Rand, P. P. and M. J. Viljoen. 2000. Developmental level of black first-year nursing students: Research. Health SA 5(2): 11-17.

Fraser, W. J. and R. Killen. 2003. Factors influencing academic success or failure of first-year and senior university students: Do Education students and lecturers perceive things differently? South African Journal of Education 23(4): 254-263.

Fraser, W. J. and R. Killen. 2005. The perceptions of students and lecturers of some factors influencing academic performance at two South African universities. Perspectives in Education 23(1): 25-40. 
Ivankova, N. V., J. W. Creswell and V. L. Plano Clark. 2011. Foundations and approaches to mixed methods research. In First steps in research, ed. K. Maree, 256-280. Pretoria: Van Schaik.

Johnson, B. and L. Christensen. 2012. Educational research: Quantitative, qualitative and mixed approaches. 4th edition. Thousand Oaks, London, New Delhi, Singapore: Sage Publications.

Killen, R., A. de K. Marais and P. van Z. Loedolff. 2003. Success and failure in distance education: Perceptions of South African students and lecturers in Business Management. South African Journal of Higher Education 17(2): 147-158.

Lourens, A. and I. P. J. Smit. 2003. Retention: Predicting first-year success. South African Journal of Higher Education 17(2): 169-176.

Miller, R., J. Bradbury and G. Lemmon. 2000. Justifying means with ends: Assessment and academic performance. South African Journal of Higher Education 14(1): 166-173.

Modipane, M. C. 2011. Initial experiences of first entering students at the university of Limpopo: Implications for coping with academic work/studies. South African Journal of Higher Education 25(8): 1592-1607.

Morosanu, L., K. Handley and B. O’Donovan. 2010. Seeking support: Researching first-year students' experiences of coping with academic life. Higher Education Research and Development 29(6): 665-678.

Muller, H., E. Swanepoel and A. de Beer. 2010. Success profiling: A methodological perspective on the interactive nature of success predictors on student performance at an open and distance learning institution. Perspectives in Education 28(2): 64-74.

Ngidi, D. P. 2007. Students' and lecturers' perceptions of some factors influencing students' academic success or failure at a historically black university in South Africa. South African Journal of Higher Education 21(4): 717-732.

Nokelainen, P., K. Tirri and H. L. Valimaki. 2007. Investigating the influence of attribution styles on the development of mathematical talent. Gifted Child Quarterly 51(1): 64-81.

Ochse, C. 2003. Are positive self-perceptions and expectancies really beneficial in an academic context? Perspectives on higher education. South African Journal of Higher Education 17(1): 67-73.

Pascarella, E. T. and P. T. Terenzini. 2005. How college affects students. 2nd Edition. USA: JosseyBass.

Peterson, E. R., C. M. Rubie-Davies, M. J. Elley-Brown, D. A. Widdowson, R. S. Dixon and S. E. Irving. 2011. Who is to blame? Students, teachers and parents' views on who is responsible for student achievement. Research in Education: An interdisciplinary International Research Journal (86): $1-12$.

Petri, H. L. and J.M. Govern. 2004. Motivation: Theory, research and applications. 5th Edition. Australia, Belmont, CA: Wadsworth Thomson Learning.

Polaki, M. V. and H. J. Nenty. 2001. Gender differences in mathematics performance attributions among first year students at National University of Lesotho: Implications for access to and performance in mathematics. Journal of SAARMSTE 5: 41-52.

Punch, F. 2009. Introduction to Research methods in education. Los Angeles, New Delhi, Singapore: Sage Publications.

Schreiner, L. and E. Hulme. 2009. Assessment of students' strengths: The first step to student success. In Focus on first-year success: Perspectives emerging from South Africa and beyond, ed. B. Leibowitz, A. van der Merwe and S. van Schalkwyk, 69-78. Stellenbosch: SUN Press.

Schunk, H. D. and J. L. Meece. 2008. Motivation in education theory, research and applications. 3rd Edition. Upper Saddle River, NJ: Pearson Education.

Scott, I. 2009. First-year experience as terrain of failure or platform for development? Critical choices for higher education. In Focus on first-year success: Perspectives emerging from South Africa and beyond, edited by B. Leibowitz, A. van der Merwe and S. van Schalkwyk, 17-35. Stellenbosch: SUN Press. 
Sikhwari, T. D. 2007. The relationship between affective factors and the academic achievement of students at the University of Venda. South African Journal of Higher Education 21(3): 520-536.

Tinto, V. 1975. Dropout from higher education: A theoretical synthesis of recent research. American Educational Research Association 45(1): 89-125.

Tomai, E. and K. Forbus. 2008. Using qualitative reasoning for attribution of moral responsibility. www.qrg.northwestern.edu/papers/files/QRG-2008/fp788 (accessed 2 December 2010).

Vallerand, R. J. and F. Richer. 1988. On the use of the causal dimension scale in a field setting: A test with confirmatory factor analysis in success and failure situations. Journal of Personality and Social Psychology 54(4): 704-712.

Van Heerden, E. L., C. P. H. Myburgh, and M. Poggenpoel. 2001. Students' experiences of challenges and threats in changing epistemic contexts. South African Journal of Higher Education 15(2): 159-162.

Viljoen, C. and E. Deacon. 2013. Factors influencing first-year students' intention to stay on at an educational institution. South African Journal of Higher Education 27(1): 239-262.

Weiner, B. 1985. An attributional theory of achievement motivation and emotions. Psychological Review 92(4): 548-573.

Zulu, C. 2008. An exploratory study of first-year students at a historically black university campus in South Africa: Their academic experiences, success and failure. Africa Education Review 5(1): 3047. 